\title{
Pela necessidade da regulamentação dos refugiados ambientais: o caso Haiti-Brasil pós-terremoto de 2010
}

\section{The need for regulation of environmental refugees: the Haiti-Brazil case after the 2010 earthquake}

\author{
Rômulo Lima Silva de Góis* \\ João Vitor Gobis Verges ${ }^{* *}$ \\ Maria José Roxo
}

\section{Resumo}

Objetiva-se com este artigo subsidiar a indicação conceitual de uma nova categoria de migrantes, os "refugiados ambientais", e relacionar o aumento do fluxo mundial destes dando destaque a estopins como a vulnerabilidade socioambiental decorrente das alterações climáticas ou demais fenômenos naturais de extremo impacto. Apresenta-se o conceito de refugiados, diferenciando-o de concepções semelhantes. Demonstra-se que os "refugiados ambientais" não estão abarcados formalmente em nenhum tipo de norma internacional existente, e por isso alvitra um alargamento conceitual do refúgio. Desenvolve-se o conceito de "refugiados ambientais", seus fatores impulsionadores e suas características. Trata-se do conceito estrito e da ocorrência dos desastres naturais, e delimita-se o objeto de estudo interligando o aumento do fluxo de "refugiados ambientais" em razão da ocorrência de desastres naturais. Aponta-se em linhas gerais que os sujeitos sociais

Doutorando em Ciências Ambientais pela Universidade Nova de Lisboa, Especialista em Direito Constitucional pela Universidade de Lisboa. Possui Especialização ainda em Direito e Processo Tributário pela Universidade Potiguar, foi Graduado em Direito pela Faculdade Natalense para o Desenvolvimento do Rio Grande do Norte. Lisboa - Portugal. Email: romulo.gois@yahoo.com.br

* Doutorando em Ciências do Ambiente pela Universidade de Lisboa (ICS/FC) e Doutorando em Geografia pela FCT/UNESP - Presidente Prudente - SP (Co-tutela). Atua como docente no Instituto Federal do Mato Grosso - Campus Avançado de Guarantã do Norte. Lisboa- Portugal. Email: vitorverges@gmail.com

*.* Professora Doutora Associada do Departamento de Geografia e Planeamento Regional da Faculdade de Ciências Sociais e Humanas, Universidade Nova de Lisboa, Directora do Departamento de Geografia da FCSSH, Membro Integrado e Vice Presidente da Comissão Diretiva do eGEO, Coordenação e investigação em diversos projectos europeus, Membro da Comissão Nacional Portuguesa de Combate à Desertificação, Membro do IGBP - Portugal. Membro do Comité Cientifico da Unesco para as Ciências da Terra. Lisboa - Portugal. Email: mj.roxo@fcsh.unl.pt 
que fogem em virtude de acontecimentos climáticos e desastres naturais também devem ser considerados "refugiados". Apresentam-se dados sobre o terremoto ocorrido no Haiti em 2010 e se demonstra o aparecimento de uma nova rota migratória de haitianos ao Brasil, podendo ser indício de que esses migrantes são os primeiros refugiados ambientais do século XXI naquele país. Apresenta-se a regulamentação anômala estatal brasileira à migração haitiana pós-terremoto de 2010 e se defende que os migrantes sejam tratados como "refugiados ambientais".

Palavras-chaves: Desastres naturais. Migração internacional. Refugiados ambientais. Alterações climáticas.

\section{Abstract}

It aims to support the conceptualization of a new category of migrants, "environmental refugees", and relate the increasing global flow of these because of the socio-environmental vulnerability due to climate change. Introduces the concept of refugees and differentiates it from similar concepts. Demonstrates that "environmental refugees" are not covered formally in any existing international law, and therefore recommends setting a conceptual extension of refuge. Develops the concept of "environmental refugees", the boosters factors and characteristics. It treats strict concept and occurrence of environmental disasters and delimits the object of study linking the increased flow of "environmental refugees" because of the occurrence of environmental disasters. Argues that humans fleeing due to climatic events and environmental disasters should also be considered "refugees". Presents data about the earthquake in Haiti in 2010 and demonstrates the emergence of a new migratory route of Haitians in Brazil, which may indicate that these migrants are the first environmental refugees of the $X X I$ century that country. Presents the Brazilian state regulations anomalous Haitian migration post-2010 earthquake and argues that migrants are treated as environmental refugees.

Keywords: Natural hazards. International migration. Environmental refugees. Climate change.

\section{Introdução}

O agravamento das alterações climáticas em diferentes regiões do planeta, com graus de intensidade diversos, e as modificações no 
ambiente em que coabitam os seres vivos têm gerado, entre as várias discussões científicas com cunho sociológico, debates sobre a existência e possível intensificação das migrações dos seres humanos em razão de fatores ambientais.

Os grandes desastres naturais, como tsunamis e sismos que estão a acontecer em zonas com alto índice de povoamento, reacendem a hipótese sobre a influência desses eventos nos deslocamentos em massa dos atingidos diretamente pelos desastres.

Estudos recentes sobre questões climáticas e desastres naturais evidenciam cenários nos quais se projetam a possibilidade de mudanças expressivas no cotidiano de milhões de pessoas que poderão ser atingidas de diversas formas pelo aumento do fluxo e movimento populacional, em decorrência das problemáticas ambientais (IPCC, 2013; AMBRIZZI et al., 2007; MARENGO et al., 2009).

As Nações Unidas, através do Alto Comissariado para Refugiados - ACNUR ([2013]) estimam que mais de 43 milhões de pessoas, em todos os continentes, constituem solicitantes de refúgio, enquadrandose como refugiados, apátridas, deslocados internos ou repatriados.

Já Bogardi (2007), ao utilizar dados da Organização Internacional para as Migrações (OIM), projeta que o número de migrantes, de todos os gêneros, totalizaria 191 milhões de pessoas.

Se observados isoladamente, os dados transcritos são substanciais, porém, existe um referencial que vai além das possíveis estatísticas apresentadas, mensurando que possivelmente 1 bilhão de pessoas poderão ser atingidas diretaou indiretamente pelas alterações climáticas (OIM, 2009).

Os números demonstram a gravidade do problema a ser enfrentado, e caso sejam confirmadas as projeções, os migrantes por motivos ambientais poderão constituir o maior grupo entre os já registrados pela OIM.

O movimento populacional por consequência de problemáticas ambientais tem gerado controvérsias conceituais, pois o conceito de 
"refugiados ambientais" é visto pelo Direito Internacional de formas diferentes, às vezes como migrantes tradicionais ou deslocados ambientais, ou apenas refugiados, na sua conceituação clássica.

A maioria dos migrantes, independentemente dos problemas conceituais que serão enfrentados nas próximas linhas, não tem garantia da manutenção do status quo de seus países, uma vez que possivelmente os desastres naturais e as mudanças de ordem climática obrigarão migrações para outras regiões.

O presente artigo trata os desastres naturais no seu sentido amplo, que inclui os de origem natural e os de origem humana, os quais serão caracterizados no desenvolvimento do texto.

Diante de tais afirmações e do contexto introduzido, tornase imperioso apresentar uma abordagem que inclua nos programas internacionais de proteção as pessoas que se deslocam por problemas ambientais, que saem de seus países pelo fundado temor das causas ambientais, assim como hoje os que migram por motivos de raça, religião, nacionalidade ou opinião política, tendo em vista a proporção que poderá representar tal grupo de migrantes no mundo.

No âmbito jurídico, essa nova categoria de migrantes assume grande relevância, em razão de estarem à margem de toda e qualquer proteção por norma específica internacional, pois a regulamentação existente não inclui como refugiado esses novos grupos de pessoas.

Tem-se, assim, por objeto do presente artigo a discussão ampla em torno de uma nova categoria de migrantes, denominados "refugiados ambientais". E é nesse passo que se traz como corte epistemológico pragmático a análise sobre os possíveis primeiros refugiados ambientais do século XXI no Brasil, os migrantes haitianos, que desde 2010 entram no país em razão da desigualdade, da complexidade estrutural da política e da economia presentes no Haiti, agravadas pelo forte terremoto ocorrido.

Dessa maneira, dar-se-á destaque às relações ambientemigrações, estendendo essa questão para que se possa argumentar 
em torno do peso relativo dos acontecimentos naturais em áreas com elevadas fragilidades econômica, social e política. Obviamente, os fatores sócio-históricos possuem ligações diretas com as migrações internacionais, contudo, se estabelecerá uma relação causa-efeito para dialogar com as possibilidades contemporâneas que se averiguam em cenários de alterações climáticas e outros acontecimentos físicos com determinações ambientais.

Assim sendo, o caso da migração dos haitianos ao Brasil é paradigmático, porque, além dos baixos índices sociais e econômicos que imperam no Haiti, um dos países com menor Índice de Desenvolvimento Humano do mundo, o terremoto em 2010 matou centenas de milhares de pessoas e deixou tantas outras desabrigadas, exigindo resposta rápida e coordenada para uma situação complexa, que representa um desafio humanitário imposto por um desastre natural.

Em decorrência do desastre e do surgimento da rota migratória, associadamente com determinações prévias em aspectos econômicos e sociais, surge, concomitantemente, a necessidade de uma resposta, que deve partir não só do país diretamente envolvido como também do país destino dos migrantes, e tal situação exige um imediatismo governamental para o qual o Brasil não estava preparado, por exemplo.

\section{Desastres naturais e fluxos migratórios}

O presente tópico tratará sobre conceituações utilizando um conceito amplo de desastres naturais, que envolve a participação das pessoas como um dos vetores da degradação ambiental que impulsionam desastres e acabam por afetar os próprios indivíduos, além dos eventos naturais, como terremotos, tsunamis, tempestades, entre outros que estão circunscritos no conceito estrito de desastre natural (TONBIN e MONTZ, 1997; UNDP, 2004; MARCELINO, 2008).

Numa conceituação estrita, Saraiva (2012, p. 21) propõe: "Um desastre natural é um acontecimento (mais especificamente a concretização de um perigo) que resulta de processos naturais da Terra 
ou que a afeta levando à perda de vidas humanas, ocorrência de feridos ou ainda a perdas económicas e ambientais."

Apresentados tais conceitos, é necessária a associação entre ocorrência de desastres naturais, questões socioeconômicas prévias e fluxos migratórios, já que uma das possíveis consequências de um acontecimento catastrófico é o deslocamento em massa da população atingida, não só em decorrência do desastre natural em si, mas, por exemplo, num possível cenário de exploração e esgotamento de recursos naturais de uma região, que faz gerar indiretamente o fluxo de fugitivos da área já desgastada.

Myers (2012) afirma que há uma forte probabilidade de fluxos migratórios em razão de desastres naturais, devido ao aumento do número de indivíduos com restrições ao acesso a recursos naturais.

Essa população mais vulnerável, que vive em ecossistemas já debilitados, como os agricultores das zonas semiáridas do norte da África, passaria a não ter mais condições de viver num território ambientalmente sensível, seja por questões naturais ou sociais, e a insustentabilidade pioraria ainda mais com as dinâmicas climáticas contemporâneas, ocasionando um movimento populacional de uma região para outra. 0 número de migrantes poderia chegar aos 200 milhões, numa visão mais otimista, caso comparada ao número apresentado pela OIM (MYERS, 2012).

Esse posicionamento é compartilhado por Warner et al. (2010). Os autores asseveram que se os sistemas socioeconômicos dependentes do meio ambiente sofrerem mudanças significativas em razão das alterações climáticas, poderão gerar movimentos populacionais muito significativos.

Neste passo, é importante a contextualização realizada por Reuveny (2007) ao indicar que os países com instabilidades econômicas surgem como áreas mais vulneráveis e enfrentarão problemas populacionais drásticos, incluindo dificuldades relacionadas à segurança 
alimentar, à saúde, ao declínio econômico, à degradação dos recursos hídricos e dos solos, possíveis ocasionadores de migrações.

Através dessas referências, fica evidenciada a premissa de que poderão ocorrer migrações por questões ambientais agravadoras de fatores socioeconômicos já debilitados, e a transformação do ambiente, seja por vetorização humana, seja por desastres de ordem natural, poderá forçar o movimento de pessoas, como no caso dos haitianos que chegaram ao Brasil, tornando-se necessário encontrar novas soluções para desafios novos.

Esse é um debate pós-moderno que atrai cada vez mais olhares midiáticos, e a repercussão se torna maior quando ocorrem desastres com grandes consequências regionais, aumentando a possibilidade de fluxos migratórios e gerando uma pressão para setores políticos regulamentadores e protetores de direitos humanos que necessitam ampliar o conceito abstrato e clássico de refugiados para enfrentar situações fáticas que poderão ser mais frequentes.

\section{Refugiados ambientais}

A interligação entre desastres naturais, migrações e direitos humanos torna-se necessária e passa por um obrigatório corte epistemológico transversal que possibilite uma visão multidisciplinar, envolvendo inclusive o ordenamento jurídico internacional, que surge como instrumento para enfrentar as problemáticas circundantes ao tema.

O primeiro questionamento é de natureza conceitual, e neste artigo pretende-se trazer alguns conceitos para possibilitar a conclusão de que o Brasil pode estar recebendo seus primeiros refugiados ambientais do século XXI. Assim, tratar-se-á de: refugiados ambientais, refugiados, deslocados internos, migrantes ambientais e migrantes.

Conforme o Instituto de Migrações e Direitos Humanos - IMDH ([2012]), migrante é toda pessoa que se desloca de seu lugar habitual, 
de sua residência comum, para outro lugar, região ou país. Esse conceito é utilizado com frequência para designar as migrações no geral, tanto as de entrada quanto as de saída de um país, lugar ou região, não obstante utilize-se muito o termo "imigrantes" para aqueles que entram em uma área e "emigrantes" para aqueles que deixam uma área. É usual, ainda, usar o termo "migrações internas" para delimitar os fluxos de pessoas dentro de um mesmo país e "migrações internacionais" para referir-se aos fluxos entre países, além de seus limites territoriais.

Por "migrantes ambientais", numa conceituação diferenciada, a OIM (2007, p.1-2) entende:

Pessoas ou grupos de pessoas que, por motivos de mudanças bruscas ou progressivas no ambiente que afetam negativamente as suas vidas ou condições de vida, são obrigados a ter que deixar suas casas habituais, ou optar por fazê-lo, temporária ou permanentemente, e que se deslocam, quer no seu território ou no estrangeiro. (Tradução livre)

Outro conceito que precisa ser abordado é o de "deslocados internos", estabelecido pela Agência da ONU para Refugiados, a ACNUR ([2013]), como pessoas que se movem dentro de seus países e são confundidas com os refugiados. Diferentemente destes, os deslocados internos não rompem a fronteira de seus países para buscar, por exemplo, segurança.

A similitude conceitual é uma das razões pelas quais os deslocamentos populacionais dos refugiados e deslocados são tão parecidos. Eles fogem de conflitos armados, da violação de direitos humanos e da violência generalizada em determinadas regiões.

Porém, a diferença consiste no fato de que, juridicamente, os deslocados internos permanecem sob a proteção do governo dos seus países e, como cidadãos, continuam a ter, mesmo que abstratamente, a vigência dos seus direitos, sendo protegidos, ainda, pelos direitos humanos e direito internacional humanitário; já os refugiados sofrem com a cessação da proteção dos seus países. 
Convém definir, então, o que é "refugiado". De acordo com a Convenção de Genebra (1951), é aquele que, temendo ser perseguido por ter determinada raça, religião ou nacionalidade, integrar um grupo social específico ou por suas opiniões políticas, encontra-se fora do país de sua nacionalidade por não poder receber a proteção deste; ou quem, não tendo nacionalidade e estando fora do país de sua habitual residência, está incapacitado de voltar para ele.

A grande polêmica surge quando se pretende definir uma nova categoria de refugiados, os refugiados ambientais, pois é um conceito não abarcado por nenhuma norma internacional, apesar de algumas agências o considerarem e já conceituarem migrações ambientais.

Seguindo a linha conceitual proposta por Derani ([2013]):

Refugiados ambientais são pessoas que fugiram de suas casas por causa de mudanças ambientais que tornaram suas vidas ameaçadas ou insustentáveis. Em alguns casos, estas pessoas encontram novos lugares para viver em seus próprios países. Em outros casos, elas devem mudar de um país para outro buscando refúgio.

Não há reconhecimento de Estados para o termo "refugiado ambiental”, o qual só foi popularizado pela publicação pioneira de ElHinnawi (1985).

A utilização dessa expressão acaba sendo problemática, porque mistura a noção de refugiado com a de deslocado interno, ou de migrante, e ainda com a de migrante ambiental.

A não unanimidade sobre a terminologia vem principalmente da não aceitação por vários autores sobre a associação entre a motivação fática do deslocamento das populações com as causas ambientais.

Como exemplo de referências discordantes, pode-se citar Black (2001). Ele entende que ao tratarmos sobre as motivações pelas quais os deslocados migram de forma diversa, estar-se-ia esvaziando as razões reais das migrações, as que seriam hipóteses plausíveis 
de comprovação, e tais motivações para os deslocamentos sempre estariam associadas a fatores políticos ou econômicos.

Suhrke (1993) entende que na discussão sobre a terminologia adotada e sobre migrações ambientais, quando não se segue uma visão que ele chama de minimalista, a qual enxerga as mudanças ambientais como uma variável que pode contribuir para a movimentação de pessoas, adota-se uma visão maximalista, a qual tenta comprovar que a degradação ambiental já deslocou milhões de pessoas e deslocará um número cada vez maior de seres humanos.

Afetados e obrigados a se deslocarem internamente entre seus países, ou cruzando fronteiras devido aos efeitos das alterações climáticas, de desastres naturais ou da simples insustentabilidade dos seus habitats, são obrigados a deixar sua história e nação para trás, num planeta onde, conforme estatísticas apresentadas por Emmot (2013), quase metade da população sobrevive com US\$2/dia, recursos naturais são utilizados num volume $30 \%$ maior que sua capacidade de renovação e a projeção de crescimento populacional prevê que se atinja 9 bilhões de pessoas em 2050.

Tais constatações lançam problemáticas a partir das quais se torna factível que, apesar da existência de limites geográficos, na realidade, não existem fronteiras para os efeitos das dinâmicas climáticas e dos prováveis deslocamentos populacionais ocasionados.

A tentativa de se colocar em pauta as problemáticas que envolvem os "refugiados ambientais" é constante nas agendas das organizações internacionais, mas estas inserem as discussões em painéis sobre o clima, cujo objetivo central dos debates está voltado aos esforços para mitigação das alterações climáticas, ou seja, ações para combater as emissões de gases que provocam o efeito estufa.

A grande dificuldade de incluir teses ou hipóteses que considerem os "refugiados ambientais" nos debates internacionais é tentar entender e comprovar como a degradação ambiental e as alterações climáticas podem ser consideradas fatores motivadores dos deslocamentos de 
seres humanos, já que quase sempre as questões econômicas, sociais e políticas se sobrepõem aos fatores ambientais.

Teorizadores consideram e já debatem três categorias de "refugiados ambientais": aqueles atingidos pelo aumento do nível do mar, os que fogem da desertificação e as vítimas de conflitos ambientais. É difícil, por outro lado, associar a degradação ambiental ou as alterações climáticas ao surgimento de fluxos migratórios.

Não se pode, neste atual momento de avanço científico sobre a matéria, menosprezar as consequências das alterações climáticas às populações com menor poder econômico, que, paradoxalmente, contribuíram pouco para a emissão de carbono no planeta e, por isso, não possuem responsabilidade histórica pela atual situação de crise climática vivenciada pela humanidade; entretanto, serão igualmente ou mais fortemente afetadas pelas consequências do aquecimento global.

Se nos países menos vulneráveis os efeitos dos desastres naturais são de forte impacto no cotidiano social e econômico, numa nação mais vulnerável e menos resiliente, eles aparecem como fatores críticos de risco.

Consideradas todas as consequências que podem ocorrer, surge a necessidade de que políticas públicas sejam realizadas para mitigar a aflição das pessoas que poderão ser atingidas e, ocasionalmente, poderão constituir um grande grupo de indivíduos migrantes.

Como, então, não considerar premissas ambientais como fatores impulsionadores de migração humana se, teoricamente, faz-se um esforço conceitual para tentar dissociar as migrações por causas ambientais das ocasionadas por fatores políticos ou sociais?

Fica manifesto que o discurso por trás da dissociação e não aceitação de expressões novas para os migrantes ou da atualização e modernização da Convenção de Genebra é defendido por teses que visivelmente são direcionadas à declinação da responsabilidade de Estados na obrigação de concessão de asilo ou refúgio aos que porventura necessitem. 
Por esses motivos, dissensos e razões expostos, torna-se necessária a exposição de premissas que tendem a estender a lei e a assistência humanitária aos que migram em razão de desastres naturais, utilizando para tal o exemplo do desastre haitiano e o fluxo migratório para o Brasil, já que a normatização no país ocorreu de forma anômala e este passou a enfrentar a situação de modo emergencial.

Não só porque o Haiti é um caso paradigmático em relação à temática da migração, sendo um país historicamente responsável por emigrações, mesmo antes do terremoto de 2010, mas também porque o Brasil poderá enfrentar no futuro outros fluxos migratórios, à medida que os desastres naturais poderão se tornar mais frequentes, devido à mudança do clima e pela degradação do ambiente.

\section{O desastre haitiano em 2010: o fluxo migratório de refugiados ambientais haitianos ao Brasil}

A imigração de haitianos para o Brasil teve número recorde em 2013 e triplicou em relação ao ano anterior. Conforme dados do IMDH ([2012]), na cidade de Brasileia, no Acre, foi registrado pela Polícia Federal o cadastro de imigrantes em 6 mil pedidos de entrada.

Importante notar que os imigrantes percorrem uma rota que passa pela República Dominicana, Panamá, Equador e Peru até chegarem ao Brasil, percurso que envolve transporte terrestre, aéreo e fluvial, pois quando não chegam à cidade de Brasileia, entram no Brasil pela cidade de Tabatinga, no Amazonas, tendo que atravessar o Rio Solimões.

A rota, monitorada e descoberta pela Polícia Federal brasileira, demonstra que os haitianos saem, na grande maioria, da capital do Haiti, Porto Príncipe, seguem através de transporte rodoviário até Santo Domingo, capital da República Dominicana, que fica na mesma ilha, e de lá compram passagem aérea até o Panamá. Da cidade do Panamá, eles seguem de avião ou ônibus até a capital equatoriana, Quito, e por fim vão à fronteira peruana, onde passam pelas cidades de Piiura, Lima, Cuzco, Iñapari, até a cidade de Brasileia (IMDH, [2012]). 
Como esses países não exigiam formalização para entrada em seus territórios (o Peru introduziu a exigência de visto em janeiro de 2012 e o Equador mantém a não exigência de visto), esses migrantes não encontravam dificuldades na entrada (IMDH, [2012]).

Para lidar com a problemática crescente, o governo brasileiro tomou como providência inicial a organização de um acampamento humanitário que, desde 2010, recebeu mais de 10.800 haitianos (IMDH, [2012]).

A Secretaria de Direitos Humanos do Estado do Acre, representante e coordenadora do acampamento de acolhimento dos haitianos, afirma que o número de imigrantes que chegam à fronteira brasileira é crescente, e a necessidade da adoção de procedimentos especiais surgiu em 2010, assim como a necessidade de construção do acampamento (IMDH, [2012]).

O fluxo migratório ao Brasil começou em janeiro de 2010, sendo esse marco temporal um dado fundamental para a compreensão e caracterização do fenômeno como a possível primeira migração do século XXI ao Brasil de refugiados ambientais em razão de um desastre natural de grande magnitude.

No mesmo mês, ocorreu um forte terremoto no Haiti que deixou 220 mil mortos, 300 mil feridos e 1,3 milhões de flagelados, destruindo grande parte do país (UNISDR, 2010).

Após o desastre, a Polícia Federal de Brasileia recebeu registro e pedido de entrada de 37 haitianos, constituindo a primeira investida de refugiados haitianos ao Brasil. Nos anos subsequentes, o número de pedidos aumentou exponencialmente (UNISDR, 2010).

Em 2011, conforme dados do Ministério da Justiça, foram 982 pedidos de visto por parte de haitianos; em 2012 o número subiu para 2.318 pedidos; e de janeiro a setembro de 2013, conforme mencionado, o número chegou a 6 mil pedidos. O fluxo migratório fez com que o governador do Acre decretasse situação de emergência social em razão 
da entrada maciça de estrangeiros no estado e dos gastos inesperados de $R$ \$ 3 milhões para administrar a situação de entrada dos haitianos.

O governo brasileiro preparou uma força-tarefa na cidade para acelerar a regularização dos imigrantes ilegais, a fim de que eles pudessem entrar e seguir para o restante do país. Na ausência de uma legislação específica para lidar com esse caso novo no cenário político-internacional brasileiro, a Polícia Federal foi orientada, através Resolução Normativa de $n^{\circ}$ 102/2013, a adotar procedimento anômalo e específico para os migrantes haitianos.

Tal resolução acabou expressamente com o limite de concessão de visto anteriormente imposto pela administração pública, que era de 1.200 vistos para haitianos. O procedimento de concessão passou a ser uma entrevista individual a cada migrante e a expedição de um protocolo preliminar que os tornam "solicitantes de refúgio".

Tal protocolo passou a garantir imediatamente os mesmos direitos que cidadãos brasileiros, como direito à saúde e à educação, sendo possibilitada, ainda, no mesmo ato, a emissão de documento hábil para trabalho, o cadastro fiscal e a emissão de passaporte do país de origem, em caso de inexistência.

Após registro prévio na Polícia Federal, os dados e documentações seguem para o Conselho Nacional de Imigração (CNIg) e para o Comitê Nacional de Refugiados (Conare), que instauram um novo procedimento para avaliar a concessão de residência permanente em caráter humanitário, com validade de até 5 anos.

Segundo dados do CNIg (2014), confrontando com os pedidos acumulados até 2012, na segunda fase do procedimento adotado para os haitianos, foram autorizados 4.628 vistos de residência permanente.

Em face do procedimento específico e anômalo, os migrantes do Haiti não são considerados refugiados pela legislação brasileira, a qual tem entendimento pacificado que somente pode ser tratado e caracterizado como refugiado aquele que provar a migração por perseguição racial, religiosa ou política. 
O governo brasileiro, na ausência de legislação regulamentadora, abriu uma exceção administrativa na concessão de vistos diferenciados, não tratando a entrada dos haitianos como ilegal.

Com o surgimento dessa rota internacional migratória, é necessário enfrentar as motivações de tal fenômeno, com a finalidade de demonstrar que a migração, para além do caráter essencialmente social, constitui a primeira que conduz refugiados ambientais ao Brasil. Eles migram em razão do desastre natural que ocorreu no país em 2010, o qual agravou a já debilitada situação socioeconômica local, e necessitam de um tratamento diferenciado, o que enseja uma nova regulamentação e mudança legislativa no Brasil, para o acolhimento seguro dos migrantes.

A situação humanitária dos haitianos no Brasil não deve admitir confusão em relação aos regimes jurídicos e às políticas públicas destinadas às tipologias dos refugiados. Se os refugiados ambientais fogem - e, no caso dos haitianos, fugiram por um desastre natural agravador de um histórico econômico e social degradante-, os refugiados tradicionais migram por perseguições perpetradas há séculos.

No caso da migração haitiana, existe um gatilho ambiental evidente que provocou a saída deles em massa, o terremoto de 2010, porém, antes de tal evento, o Haiti já exemplificava um caso paradigmático de degradação ambiental crônica. De acordo com o retratado por Dolisca et al. (2007) sobre a degradação anterior, pode-se concluir que o desastre natural acontecido amplificou uma situação ambiental dramática já presente.

O ACNUR ([2013]), oito meses após o terremoto, reconheceu a situação e o regime jurídico de deslocados internos aos 1,3 milhões de haitianos que tiveram suas moradias destruídas e passaram a viver nos 1.354 acampamentos e assentamentos na zona metropolitana da capital do Haiti, Porto Príncipe.

Em números estatísticos, para clarificar a amplitude do evento catastrófico, ao menos $60 \%$ dos prédios governamentais, administrativos 
e econômicos foram destruídos; 180 mil residências colapsaram; 23\% das escolas foram danificadas, sendo $80 \%$ na capital (UNHCR, 2010).

O reconhecimento pelo Alto Comissariado das Nações Unidas da situação dos que não migraram não resolve a problemática apresentada ao Brasil. Preliminarmente, os refugiados ambientais haitianos poderiam, pela legislação interna brasileira, através do Estatuto do Estrangeiro Lei $n^{\circ} 6815 / 80$, ter sido tratados somente como imigrantes e trabalhar regularmente no Brasil, com base no Estatuto do Estrangeiro, caso fossem preenchidos alguns requisitos legais e houvesse um lapso temporal de residência. Entretanto, a motivação para mais de 6.000 haitianos entrarem no Brasil não se trata apenas de uma questão econômica com forte viés humanitário, mas também ambiental.

Num primeiro momento, tentou-se o enquadramento jurídico como refugiados, negado pelas instâncias administrativas e legais brasileiras, pois não preenchiam os requisitos da Convenção de Genebra, nem da lei brasileira, que a recepcionou no ordenamento interno, Lei n 9474/97.

Posteriormente, outro dimensionamento foi proposto e apresentado pelas próprias instâncias administrativas: os haitianos precisariam enviar seus pedidos ao CNIg, que autorizaria a concessão de residência permanente por motivos humanitários, baseado na resolução normativa $n^{\circ}$ 97, de 12 de janeiro de 2012, que dispõe sobre a concessão de visto permanente, previsto no art. 16 do Estatuto dos Estrangeiros à nacionais do Haiti.

Diante desse contexto, dos mais de 5.200 pedidos de "refúgio" apresentados formalmente por haitianos, foram aprovados 4.628 processos, concedendo-lhes, como já referido, residência permanente por motivos humanitários.

Porém, tal retalho jurídico e político não é suficiente para a situação inédita apresentada no ordenamento jurídico e social do Brasil, a qual poderá se tornar, em médio e longo prazo, uma celeuma factual constante que precisará ser enfrentada com ampla regulamentação legal, para garantir segurança jurídica aos envolvidos. 


\section{Por uma nova conceituação jurídica internacional de refugiados ambientais}

Não existe pacificação doutrinária sobre a conceituação do que seriam os refugiados ambientais, necessitando que se avance em estudos na defesa de uma nova conceituação jurídica internacional, abarcando e gerando proteção aos que migram e chegam a outro Estado por gatilhos ambientais extremos.

Como defende Black (2010), as questões ambientais ocasionadoras das migrações sempre estão influenciadas por alguma motivação política ou econômica, ligadas também ao meio ambiente, constituindo tal relação uma verdadeira cadeia de motivos e fatos determinantes que atingem os envolvidos.

Seguindo proposta de Ramos et al. (2011), o presente artigo entende que, de forma isolada, a promulgação de leis não vai resolver o problema dos refugiados ambientais, por isso, as medidas e políticas públicas adotadas devem ser norteadas por valores e princípios que guiam a humanidade.

A proteção aos refugiados ambientais, desta feita, deve ser observada por um viés jurídico, com base em princípios e alicerçada prioritariamente no Princípio da Solidariedade e no Princípio da Dignidade da Pessoa Humana.

O Princípio da Solidariedade, previsto expressamente na Constituição brasileira, determina um dos objetivos fundamentais do Estado, qual seja, formar uma sociedade livre, justa e solidária.

Demoliner (2011) assevera que esse princípio, em panoramas de desastre naturais, possibilita que os particulares, observadas suas condições reais, prestem auxilio e façam uma ação positiva impulsionada por um dever supralegal, pelo dever da solidariedade e de ajuda aos necessitados. Tal princípio deve nortear o Estado, para que indenize os que prestam auxílio aos necessitados e, ainda, nortear a comunidade internacional e os órgãos regularmente estabelecidos, 
para que despendam toda ajuda necessária e possível para minimizar os danos aos atingidos pelo fato ocorrido.

Por outro lado, deve-se preservar a integridade dos atingidos por desastres naturais, e para isso, a observância de um segundo alicerce que garanta condições mínimas de vivência e convivência deve ser defendida, qual seja, a prevalência do Principio da Dignidade da Pessoa Humana às situações sociais enfrentadas.

Da mesma forma que o princípio tratado anteriormente, a Constituição brasileira aponta como alicerce fundamental do Estado Democrático de Direito a Dignidade da Pessoa Humana.

Esse princípio deve ser assegurado a todos os seres humanos, independentemente de nacionalidade, raça, ou religião, bastando sua existência como condição para tal.

Martins (2012) acerta ao afirmar que, longe de ser um trunfo jurídico para as diversas situações em que é evocada, a Dignidade da Pessoa Humana impede que o ser humano seja alvo de quaisquer situações desumanas ou degradantes, garantindo-lhes acesso e condições mínimas de existência.

Há um razoável consenso na doutrina jurídica de que direitos mínimos devem ser garantidos aos "refugiados ambientais" pelo Estado e pela sociedade. Se como medida protetiva ampla devem-se garantir os dois princípios gerais de Direito tratados, como alternativa protetiva, é preciso enumerar algumas soluções para oferecer segurança jurídica aos que migram e pedem refúgio por motivação ambiental.

Cournil (2009) propõe a elaboração de um novo protocolo que reforme a Convenção de Genebra e expanda o conceito de refugiado prescrito nessa norma internacional, para incluir na categoria os migrantes e refugiados ambientais.

A proposição da reforma tem o objetivo de estabelecer um novo compromisso entre Estados - o qual se daria através de uma nova Convenção, baseada em princípios gerais de Direito -, que não fizesse distinção entre as causas que motivaram o deslocamento de quem pede 
refúgio e objetivasse diminuir as implicações negativas das migrações, além de adotar medidas para abrandar as causas que as incentivam, impondo responsabilidade aos Estados que mais motivam deslocados.

A tese exposta por Cournil (2006 apud JESUS, 2009, p. 90-95) defende a reforma da Convenção de Genebra e propõe, ainda, a inserção de normas que gerem obrigação aos Estados atingidos e permitam a proteção imediata, com a intervenção de órgãos internacionais, para possibilitar a prestação de auxílio e assistência em território estrangeiro.

Por outro lado, algumas políticas públicas voltadas aos afetados por desastres ambientais podem ser desenvolvidas em âmbito local, corroborando com a máxima de que, apesar de os problemas ambientais das alterações climáticas serem globais, eles podem ser minimizados na multiplicidade de ações regionais e locais.

Para ilustrar e exemplificar uma política de âmbito local, no Rio Grande do Sul, o Departamento Municipal de Habitação de Porto Alegre (DEMHAB) desenvolveu uma solução emergencial voltada aos atingidos por um desastre natural: o "Aluguel Social" e as "Casas de Emergência” (PORTO ALEGRE, 2011).

O "Aluguel Social" é uma política pública de provimento de um recurso mensal pelo período de cinco meses, equivalente ao valor de um arrendamento residencial popular, oferecido sem ônus às famílias que não tenham moradia fixa e estejam alocadas em áreas de risco, de preservação ambiental ou atingidas diretamente por desastres naturais (PORTO ALEGRE, 2011).

Inúmeras famílias são beneficiadas, a exemplo dos moradores da Vila dos Sargentos, que foram remanejados para locais seguros recebendo o benefício do "Aluguel Social", por antes residirem às margens do Rio Guaíba, área de monitoramento constante pelos riscos de deslizamentos e alagamentos (PORTO ALEGRE, 2011).

As "Casas de Emergência", outra política pública desenvolvida pelo DEMHAB, têm minimizado as necessidades dos atingidos por desastres naturais. Tal provimento consiste em um programa específico 
de doação de materiais, como telhas, chapas de compensado, pregos, dobradiças e material elétrico para a construção de pequenas casas de emergência - tamanho padrão de 2,70 por 3,30 metros (PORTO ALEGRE, 2011).

As medidas exemplificadas servem para demonstrar como, em âmbito local, políticas públicas podem ser desenvolvidas para atender às necessidades imediatas de quem sofreu perdas por causas ambientais.

Analisando-se tanto por um referencial amplo de governança global quanto por um menor, de governança local, importa concluir, nas palavras de Morin (2013), que a humanidade enfrenta um conjunto de crises que requer a reflexão crítica em relação ao conceito do que vem a ser desenvolvimento.

Morin (2013) adverte sobre a obrigação de enfrentarmos entraves que permitam a existência de poderes supranacionais, lembrando que as Nações Unidas deveriam instituir uma declaração de interdependência planetária, tendo em vista a não consideração de barreiras ou limites geográficos pelos desastres naturais ou pelas alterações climáticas.

Os Estados possuem obrigações comuns de auxiliar os refugiados por motivos ambientais e as populações que, no futuro, sofrerem os efeitos das alterações climáticas.

Necessita-se, entretanto, daqueles Estados que, através de suas ações ou omissões, tiveram um grau maior de participação na origem dos eventos que resultaram em migrações, de modo que tenham obrigações e uma responsabilidade diferenciada, permitindo que os países atingidos e alvos de migrações minimizem as consequências das alterações em seu ambiente e mitiguem os efeitos econômicos e sociais à população, garantindo um reassentamento seguro e eficiente nos casos em que não seja possível o retorno dos que pedirem refúgio.

\section{Conclusão}

Como se pode concluir, não existe pacificação conceitual acerca das definições e terminologias, nem mesmo reconhecimento das 
instâncias internacionais sobre a expressão "refugiado ambiental" como termo que represente quem é levado a deslocar-se e cruzar uma fronteira internacional por estopins ambientais que agravam suas condições sociais e econômicas já frágeis, como os desastres naturais.

Mesmo que se necessite admitir que as motivações para migrações por questões ambientais estejam relacionadas, também, com causas políticas ou econômicas, não se pode ignorar que um número crescente de indivíduos está sendo atingido por mudanças ocorridas no meio ambiente, provocando deslocamentos populacionais.

Mudanças que atingem nações a ponto de fazer surgir uma nova rota migratória, como a rota para o Brasil, daqueles que poderão ser considerados os primeiros refugiados ambientais do século XXI: os haitianos que saíram do seu país devido ao terremoto de 2010.

É fundamental que, superadas as problemáticas conceituais que circundam e engessam a Ciência, aprimorem-se políticas públicas de ajuda mútua entre as nações envolvidas, visando reduzir os impactos advindos de desastres naturais e migrações forçadas dos atingidos.

É nesse ponto que a redução dos impactos pode ser proporcionada pelo avanço da Ciência Jurídica e do Direito Internacional, no sentido de possibilitar a construção de estratégias que garantam a adaptação dos grupos atingidos por desastres naturais às novas situações vivenciadas, através do desenvolvimento de mecanismos jurídicos.

A Ciência Jurídica e as áreas correlatas envolvidas nas problemáticas expostas, a exemplo da Ciência Política, da Sociologia e da Geografia, surgem como guardiãs da efetiva proteção dos refugiados ambientais, pois cabe a elas construir estruturas políticas, sociais e legais que ofereçam proteção e garantam um tratamento aos atingidos, respeitando os princípios da dignidade da pessoa humana e da solidariedade. 


\section{Referências}

ALTO COMISSARIADO DAS NAÇÕES UNIDAS PARA REFUGIADOS (ACNUR). Disponível em: <http://www.acnur.org/t3/portugues/ informacao-geral/breve-historico-do-acnur/>. Acesso em: 9 out. 2013.

. Breve histórico do ACNUR. Disponível em: <http://www.acnur. org/t3/portugues/informacao-geral/breve-historico-do-acnur/>. Acesso em: 25 nov. 2013.

MARENGO, J. A. Cenários regionalizados de clima no Brasil para o Século XXI: projeções de clima usando três modelos regionais: Relatório 3. In: BRASIL. Ministério do Meio Ambiente. Mudanças climáticas globais e efeitos sobre a biodiversidade - Sub projeto: Caracterização do clima atual e definição das alterações climáticas para o território brasileiro ao longo do Século XXI. Brasília, 2007. p. 91120.

BLACK, Richard. Environmental refugees: myth or reality? New issues in refugee research. Geneva: United Nations High Commissioner for Refugees, 2001. (Working paper, n. 34)

BRASIL. Conselho Nacional de Imigração. Resolução normativa $n^{\circ}$ 102/2103 de 26 de abril de 2013. Altera o art. $2^{\circ}$ da Resolução Normativa ${ }^{\circ} 97$, de 12 de janeiro de 2012. Disponível em: <http:// www.legisweb.com.br/legislacao/?id=253792>. Acesso em: 8 out. 2013.

BRASIL. Conselho Nacional de Imigração. Resolução Normativa $n^{\circ} \mathbf{9 7 / 2 0 1 2}$ de 12 de janeiro de 2012. Dispõe sobre a concessão do visto permanente previsto no art. 16 da Lei $n^{\circ} 6.815$, de 19 de agosto de 1980, a nacionais do Haiti. Disponível em: < http://portal. mte.gov.br/data/files/8A7C816A350AC8820135687F345B412D/ RESOLU\%C3\%87\%C3\%83O\%20NORMATIVA\%20N\%C2\%BA\%2097. pdf>. Acesso em: 9 out. 2013.

BRASIL. Lei 6815/80 - Estatuto do Estrangeiro, de 19 de agosto de 1980. Define a situação jurídica do estrangeiro no Brasil, cria o Conselho Nacional de Imigração. Diário Oficial da República 
Federativa do Brasil, Brasília, 21 ago. 1980. Disponível em: <http:// www.planalto.gov.br/ccivil_03/leis/l6815.htm>. Acesso em: 9 out. 2013.

BRASIL. Lei 9474/97 de 22 de julho de 1997. Define mecanismos para a implementação do Estatuto dos Refugiados de 1951, e determina outras providências. Diário Oficial da República Federativa do Brasil, Brasília, 23 jul. 1997. Disponível em: <http://www.planalto.gov. br/ccivil_03/Leis/L9474.htm>. Acesso em: 9 out. 2013.

BOGARDI, Janos et al. Control, adapt or flee. How to face Environmental Migration? UN Intersections, Bornheim, n. 5, 2007.

BRASIL. Conselho Nacional de Imigração. CNIg prorroga concessão de visto especial a haitianos. Disponível em: <http://portal.mte.gov. br/imprensa/cnig-prorroga-concessao-de-visto-especial-a-haitianos. htm.>. Acesso em: 8 out. 2013.

CONSELHO NACIONAL DE IMIGRAÇÃO - CNIg. Projeto Estudos sobre a Migração Haitiana ao Brasil e Diálogo Bilateral. Disponível em <http://portal.mte.gov.br/data/files/8A7C816A4AC03DE1014AE84B F2956CB6/Pesquisa\%20do\%20Projeto\%20\%E2\%80\%9CEstudos\%20 sobre $\% 20$ a $\% 20$ Migra $\%$ C3\%A7\%C3\%A30\%20Haitiana $\% 20$ ao\%20 Brasil\%20e\%20Di\%C3\%A1logo\%20Bilateral\%E2\%80\%9D.pdf>. Acesso em: 24 fev. 2015.

CONVENÇÃO de Genebra. 1951. Convenção Relativa ao Estatuto dos Refugiados. Disponível em: <http://www.fd.uc.pt/CI/CEE/pm/ Tratados/Amesterdao/conv-genebra-1951.htm>. Acesso em: 5 out. 2013.

DEMOLINER, Karine Silva. O princípio da solidariedade no contexto de um estado socioambiental de direito. 225 f. 2011. Tese (Doutorado em Direito) - Faculdade de Direito, Pontifícia Universidade Católica do Rio Grande do Sul, Porto Alegre, 2011.

DERANI, Cristiane. Dicionário de direitos humanos, refugiados ambientais. Disponível em: <http://www.esmpu.gov.br/dicionario/tikiindex.php?page=Refugiado\%20Ambiental>. Acesso em: 8 out. 2013. 
DOLISCA, F.; McDANIEL, J. M.; TEETER, L. D.; JOLLY, C. M. Land tenure, population pressure, and deforestation in Haiti: The case of Forêt des Pins Reserve. Journal of Forest Economics, Umea, n. 13, v. 4 , p. $277-289,2007$.

EMMOTT, Stephen. Dez mil milhões: enfrentando nosso futuro. Lisboa: Temas e Debates - Círculo de Leitores, 2013.

EL-HINNAWI, Essam. Environmental refugees. Nairobi: United Nations Environment Programme (UNEP), 1985.

GIL SARAIVA, Jorge. Catástrofes Naturais: o que são? In: COLÓQUIO CATÁSTROFES NATURAIS: UMA REALIDADE MULTIDIMENSIONAL, 2012, Lisboa. Actas... Lisboa: Instituto de Ciências Jurídico-Políticas, 2012. p. 21-46. Disponível em: <http://www.icjp.pt/sites/default/files/ publicacoes/files/ebook_catastrofes_final1_isbn.pdf>. Acesso: 2 out. 2013

INSTITUTO DE MIGRAÇÕES E DIREITOS HUMANOS - IMDH. Resenha de Imprensa 2012. Disponível em: <http://www.migrante.org. br/IMDH>. Acesso em: 8 out. 2013.

INTERGOVERNAMENTAL PAINEL ON CLIMATE CHANGE - IPCC. Fifth Assessmente Report - AR5. Disponível em: <http://www. climatechange2013.org/images/uploads/WGIAR5_WGI-12Doc2b_ FinalDraft_All.pdf>. Acesso em: 25 nov. 2013.

INTERNATIONAL ORGANIZATION FOR MIGRATION - OIM. Migration, environment and climate change: assessing the evidence. Geneva: OIM, 2009.

INTERNATIONAL ORGANIZATION FOR MIGRATION - OIM. Migration and Environmental. Geneva: OIM, 2007. p. 1-2. Disponível em < http://www.iom.int/jahia/webdav/shared/shared/mainsite/about_ iom/en/council/94/MC_INF_288.pdf >. Acesso em: 5 out. 2013.

JESUS, Tiago Schneider de. Um novo desafio ao direito: deslocados/migrantes ambientais. Reconhecimento, proteção e solidariedade. 2009. 128 f. Quantidade de folhas Dissertação 
(Mestrado em Direito) - Faculdade de Direito, Universidade de Caxias do Sul, Caxias do Sul, 2009.

MARENGO, J. A.; JONES, R.; ALVES, L. M. et al. Future change of temperature and precipitationextremes in South America as derived from the PRECIS regional climate modeling system. International Journal of Climatology, Malden, v. 29, n. 15, p. 2241-2255, 2009.

MARCELINO, Emerson Vieira. Desastres Naturais e Geotecnologia. INPE-15208-PUD/193. INPE, São José dos Campos, 2008. Disponível em: <http://mtc-m18.sid.inpe.br/col/sid.inpe.br/ mtc-m18@80/2008/07.02.16.22/doc/publicacao.pdf>. Acesso em: 23 fev. 2015.

MARTINS, Flademir Jerônimo Belinati. Dignidade da pessoa humana: principio constitucional fundamental. Curitiba: Juruá, 2012.

MORIN, Edgar. A Via para o futuro da humanidade. Tradução de Edgar de Assis Carvalho e Mariza Perassi Bosco. Rio de Janeiro: Bertrand Brasil, 2013.

MYERS, N. Environmental refugees: a growing phenomenon of the 21st century. Philosophical Transactions of the Royal Society of London, Londres, B 357, p. 609-613, 2012.

PORTO ALEGRE. Departamento Municipal de Habitação. Famílias da vila do sargento deixam área de risco. 2011. Disponível em: <http:// www2.portoalegre.rs.gov.br/demhab/default.php?p_noticia=138131\&FA MILIAS+DA+VILA+DOS+SARGENTOS+DEIXAM+AREA+DE+RISC>. Acesso em: 25 nov. 2013.

RAMOS, André de Carvalho; RODRIGUES, Gilberto; ALMEIDA, Guilherme Assis de (Orgs.). 60 Anos de ACNUR perspectivas de futuro. São Paulo: CL-A Cultural, 2011.

REUVENY, R. Climate change-induced migration and violent conflict. Political Geography, Bloomington, n. 26. p. 656-673, 2007. 
SUHRKE, Astri. Pressure points: environmental degradation, migration and conflict. Washington: American Academy of Arts and Sciences, 1993.

THE UN REFUGEE AGENCY. Haiti: eight months after the earthquake. Geneve: UNHCR, 2010.

THE UNITED NATIONS OFFICE FOR DISASTER RISK REDUCTION. Are we capable of learning the lessons of Haiti? Disponível em: <http://www.unisdr.org/archive/24946>. Acesso em: 8 out. 2013.

TOBIN, G. A.; MONTZ, B. E. Natural hazards: explanation and integration. Nova lorque: The Guilford Press, 1997.

UNITED NATIONS DEVELOPMENT PROGRAMME. Reducing disaster risk: a challenge for development. Nova lorque: UNDP, 2004.

WARNER K.; HAMZA M.; OLIVER-SMITH A.; RENAUD F.; JULCA, A. Climate change, environmental degradation and migration. Natural Hazards, v. 55. n. 3, p. 689-715, 2010. Disponível em: <http://link. springer.com/article/10.1007\%2Fs11069-009-9419-7>. Acesso em: 10 out. 2013.

Recebido em: 03/03/2015

Aprovado em: 01/12/2015 